\title{
NOTAS PARA LA CRIMINALIZACIÓN DE ALGUNAS OFENSAS AMBIENTALES EN CHILE ${ }^{1}$
}

\author{
Dante Figueroa Hernández y Jaime Retamal Herrera \\ Universidad Diego Portales
}

\section{Introducción}

El presente trabajo tiene por objeto analizar el actual estado de la dogmática penal nacional respecto de la penalización de ofensas ambientales en general, señalar las bases para una tipificación futura de las faltantes, introduciendo en esta labor, una definición necesariamente global o integradora del valor jurídico protegido "medio ambiente".

Los autores estiman que la actual valorización social que demuestra la sociedad chilena del valor jurídico protegido, la imperiosa necesidad de conservar el entorno ambiental, y la insuficiencia, falta de coherencia y unidad lógico-jurídica de los tipos protectores indirectos del medio ambiente, son todos factores que aún considerados aisladamente, justifican la introducción de algunas figuras penales ecológicas sobre las bases que se expresan en el desarrollo del artículo.

\section{La Decisión Político-Criminal de Establecer Figuras Penales para la Protección del Medio Ambiente.}

Considerando la actual inexistencia normativa a nivel nacional, de figuras penales que propiamente puedan denominarse "delitos ecológicos" ${ }^{2}$, el objetivo de esta parte es el análisis político criminal previo de la necesidad de su incorporación, sin hacer referencia a una especial estructura típica.

Se parte de la base entonces -como es necesario conforme a los modernos criterios de intervención punitiva del Estado, y de reconocimiento de la función político criminal del Derecho Penal- de un análisis más meditado de la necesidad de la intervención penal en el ámbito del bien jurídico "medio ambiente".

Así, se plantean una serie de desafíos cuya aproximación llena de contenido el presente artículo, sobretodo teniendo a la vista la relativa relevancia que ha adquirido el tema medioambiental dentro de la comunidad nacional durante el último tiempo.

${ }^{1}$ El primero de los autores es Abogado, Master of Laws, en Derecho Ambiental, American University, Washigton D.C., Consultor del Center for International Environmental Law, Washington, D.C., y Egresado Programa de Magister en Derecho, Facultad de Derecho, Universidad de Chile; y el segundo es Penalista, Abogado del Consejo de Defensa del Estado, y Ayudante del Departamento de Derecho Penal en la Escuela de Derecho de la Universidad Diego Portales.

2 KUNSEMULLER, Carlos, "Protección Legal del Medio Ambiente: Qué enseñar, qué investigar. Legislación Chilena: Características, evolución, interés por un Derecho Penal del Entorno", en Ga. Jur. 85 (1987), p.6. 


\section{Análisis del Bien Jurídico Protegido}

\section{Generalidades:}

En términos generales, el medio ambiente puede ser regulado desde el punto de vista administrativo, económico, de responsabilidad civil, tributario ${ }^{3}$, relativo a la salud pública y, también, penal.

La regulación penal del medio ambiente nos ocupa en este artículo.

La tipificación de conductas delictuales busca la protección del medio ambiente. Esta labor requiere determinar si existe propiamente un bien jurídico penal en el medio ambiente, o mejor dicho, si aquél es calificable como un bien jurídico de relevancia penal.

Dicha tarea supone un relativo consenso para los efectos de estas líneas del contenido de la expresión de bien jurídico, y subsecuentemente, del encuadramiento dentro de esa categoría de contenidos de la expresión "medio ambiente" 3 .

Esto es de especial importancia, no solo porque toda criminalización requiere de una meditada política criminal, y dejar de lado la arraigada confianza en la represión penal mediante el expediente fácil de la tipificación de conductas, que es un fenómeno arraigado en la conciencia colectiva de la población, y de frecuente uso entre nuestro parlamentarios. Además es relevante desde la perspectiva, de que en general en todo tipo de legislación, incluso en la chilena, existen tipos penales que sancionan conductas lesivas al medio ambiente, pero en forma indirecta (Código Penal, Ley de Pesca, Ley de Bosques). Dicha protección indirecta preexistente a este análisis obliga a circunscribir muy claramente la especial o delicada afección que supone lesionar el medio ambiente como tal, y no como un accesorio a otro tipo de ilícitos. $Y$ de primera línea, requiere una predisposición para dotar al bien jurídico con un contenido ecosistémico, ya que la referencia a un concepto meramente individualista podría impedir una eficaz delimitación de esta especial categoría de ilícitos frente a otras figuras que tangencial o indirectamente realizan una protección normativa del entorno.

Con los efectos antecitados, realizaremos una revisión del contenido, naturaleza y extensión del bien jurídico protegido "medio ambiente" en la normativa constitucional y legislativa chilena recientes, con algunas referencias posteriores a definiciones existentes en Derecho Comparado.

tal

\section{Distinción entre Medio Ambiente, Recursos Naturales y Patrimonio Ambien-}

En nuestro sistema jurídico encontramos, a lo menos, tres conceptos diversos para referirse al entorno natural: el de patrimonio ambiental, el de recursos naturales, y el de medio ambiente. Debe pues, analizarse si corresponden estos conceptos a una misma idea jurídica presente en el pensamiento del legislador. Con tal objeto nos referimos a cada concepto por separado.

\subsection{Recursos Naturales}


En nuestra historia constitucional reciente, el Acta Constitucional $\mathrm{N}^{\circ} 3$ eleva la protección jurídica del medio ambiente a nivel constitucional ${ }^{4}$. Añadió, tal Acta, como deber del Estado, "la preservación de los recursos naturales", declarando que "la integridad territorial de Chile comprende la de su patrimonio ambiental. ${ }^{5 . "}$

En el orden legal, diversas normas con "relevancia ambiental" 6 y sin una coherencia orgánica utilizan la distinción entre recursos naturales y medio ambiente. Así, por ejemplo, pueden citarse la Ley General de Pesca y Acuicultura ${ }^{7}$, el Reglamento para el Control de la Contaminación Acuática ${ }^{8}$, la ley $N^{\circ} 16.615^{9}$, y el Reglamento sobre Protección de Aguas en Pro de la Agricultura y la Salud de los Habitantes ${ }^{10}$.

Pareciera ser que el legislador ha utilizado conceptos diversos sin una conexión orgánica y una lógica dogmática. En efecto, las normas legales existentes más bien parecen una respuesta específica a un fenómeno concreto cual es la depredación de los recursos naturales (baste recordar la teoría de la dependencia económica en boga desde los años 60), o para casos de contaminación específica de ciertos componentes del medio ambiente. ${ }^{1}$

Una protección del ambiente que desee tener el carácter de global no debería en caso alguno restringirse a algunos de sus elementos o componentes, en este caso, a los recursos naturales. El medio ambiente es más que eso, incluye también la Biodiversidad, la fauna, etc. ${ }^{12}$

\subsection{Patrimonio Ambiental}

${ }^{4}$ La Corte Suprema en el caso del Lago Chungará. Considerando 9 indicó que "...no puede tampoco el constituyente ignorar el peligro de la contaminación ambiental el que, aunque no tratado todavia por otras Cartas Constitucionales, implica un riesgo permanente para la vida y desarrollo del hombre", en $R C h D$. Tomo LXXXII, N³, Parte $2^{\circ}$, Secc. V.

CORDERO VEGA, Luis, "En el proyecto de LBMA, su artículo $1^{\circ}$, letra $\mathrm{m}$ ), indicaba que el 'patrimonio ambiental' comprendía 'los recursos naturales renovables y demás componentes del medio ambiente' en general. Luego del debate senatorial fue suprimida tal definición por ser considerada innecesaria. En tal sentido, el senador Piñera indicó que "la imposibilidad de definir qué es lo que se protege significa falta de conocimiento de lo que se quiere proteger $y$, por tanto, cualquier intento-legislativosería ineficaz", "Gobierno Local y Medio Ambiente", en Rev. Gob. Reg. y Mun. (1995), p.59.

${ }^{6}$ Ver Repertorio de la legislación de relevancia ambiental vigente en Chile, Santiago, CONAMA 1992, en biblioteca Dirección de Promoción de Exportaciones, Ministerio de Relaciones Exteriores, archivo 33CL - 02.07 REP.

7

El D.S. Nº1, D.O. del 18.11.92, Ministerio de Defensa Nacional, "Reglamento sobre Contaminación Acuática", en su Título X "Delitos Especiales y Penalidades", art. 135, sanciona al que "...capturare o extrajere recursos hidrobiológicos utilizando elementos explosivos, tóxicos u otros cuya naturaleza provoque daño a esos recursos o a su medio...". El art. 136, igualmente, utiliza la expresión "...que causen daño a los recursos hidrobiológicos". Art. $1^{\circ}(\mathrm{n} .7)$, señala que "El presente reglamento establece el régimen de prevención, vigilancia y combate de la contaminación en las aguas de mar, puertos, ríos y lago sometidos a la jurisdisción nacional."

9 Publicada en el Diario Oficial el 20.01.67, prescribe que "Cuando el interés de la comunidad nacional lo exija, la ley podrá reservar al Estado el dominio exclusivo de recursos naturales..."

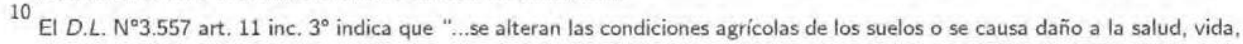
integridad o desarrollo de los vegetales o animales."

11

CORDERO (n. 5), p. 45, cita el Informe Final de la Comisión Nacional de Investigación Cientifica y Tecnológica (CONICYT) "Ideas básicas sobre protección constitucional y legal del medio ambiente y los recursos naturales",

12 Ver al efecto la Ley $N^{\circ} 19.473(D .0 .27 .09 .96)$, sobre Caza, la cual en sus artículos 30 y ss, contiene sanciones penales para el caso de algunas contravenciones. 
Sólo recientemente el Constituyente ha incorporado la idea de una protección global al medio ambiente, más allá de un simple intento de detener la depredación de los recursos naturales (minerales, pesca, bosques). En ese sentido, constituye un hito la referencia al "patrimonio ambiental" del Acta Constitucional $N^{\circ} 3$. Sin embargo, tal expresión del constituyente ha sido: [a] defectuosa, por su vinculación a la idea de "integridad territorial", que posee connotaciones más bien de soberanía política, como quedó demostrado al aprobarse la Constitución de 1980 que eliminó tal expresión. Y, además, [b] insuficiente, por su mero carácter desiderativo o programático y la falta de legislación específica que implementara tal norma constitucional.

Otra expresión legislativa en este sentido está contenida en la Ley de Bosques (D.L. 400/74) al referirse al "patrimonio forestal del país". La Corte Suprema en la sentencia sobre el Lago Chungará acuñó la misma expresión ${ }^{13}$, a nuestro juicio, sin embargo, demasiado amplio. Finalmente, la Ley 19.300, sobre Bases Generales del Medio Ambiente utiliza la voz "patrimonio ambiental" a propósito de su conservación, entendiendo por tal "...los componentes del medio ambiente, especialmente aquellos propios del país que sean únicos, escasos o representativos..."

Existe, entonces, una superación en el entendimiento tácito y lento del legislador chileno en cuanto a la necesidad de una protección global del medio ambiente ${ }^{14}$. No obstante, tales intentos, como veremos, se ven frustrados por la técnica legislativa específica utilizada. ${ }^{15}$

\subsection{El "Medio Ambiente" como Valor Jurídico Específico}

Podemos distinguir tres concepciones diversas del medio ambiente presentes en nuestro sistema jurídico, a saber:

\subsubsection{Concepción Civilista o Propietarista}

Esta noción tradicional de los Códigos Civil y Penal ha dominado nuestro ordenamiento jurídico desde mediados del siglo XIX. La distinción es básica: existen bienes públicos y bienes privados ${ }^{16}$; los primeros pertenecen a la nación toda, y los segundos

${ }^{13}$ La Corte Suprema en el caso del Lago Chungará (n. 4), ha definido medio ambiente y patrimonio ambiental como "todo lo que naturalmente nos rodea y que permite el desarrollo de la vida, y tanto se refiere a la atmósfera, como a la tierra y sus aguas, a la flora y fauna, todo lo cual conforma la naturaleza, con sus sistemas ecológicos de equilibrio entre los organismos y el medio que viven"

14

En los EE.UU., una importante Ley Federal (Comprehensive Environmental Response, Compensation and Liability Act). incorpora en su Sección 9601(8) una definición totalizante de medio ambiente: "El término medio ambiente significa (A) las aguas navegables, las aguas de la zona contigua, y las aguas oceánicas por las cuales los recursos naturales están bajo el exclusivo control de autoridad de los Estados Unidos...y (B) cualquiera otra superficie de agua, aguas a nivel del suelo, suministros de agua potable, superficies de tierra o estratos subterráneos, o aire circundante dentro de los Estados Unidos o bajo la jurisdicción de los Estados Unidos." (Trad. Dante Figueroa Hernández, 1997).

15

Las deficiencias de la estructura constitucional misma de la protección del medio ambiente en Chile, se advierte en la presentación de, por lo menos, tres proyectos de reforma constitucional en los últimos siete años; a saber: [a] Moción presentada en la Sesión $18^{\circ}$ de la Cámara de Diputados, 25.07.90, para eliminar el requisito copulativo de ilegalidad " $y$ " arbitrariedad en el Recurso de Protección Ambiental; [b] Moción presentada en la Sesión 32 del Senado, 17.01.96, para elevar el carácter de la Ley $N^{\circ} 19.300$, sobre Bases del Medio Ambiente, a Orgánico-Constitucional; y [c] Moción presentada en la Sesión $23^{\circ}$ de la Cámara de Diputados, 17.01.96, para añadir "la conservación del patrimonio ambiental", dentro de la garantía constitucional del Artículo $19 \mathrm{~N}^{\circ} 8$.

16 Ver Artículo 582 y ss, del Código Civil. 
quedan dentro del patrimonio individual. Los recursos naturales tendrán la calidad de públicos o privados en cuanto sean apropiados o no por particulares.

Esta perspectiva es, eminentemente, individualista pues entiende la protección del medio ambiente como relacionado con la subsistencia de la especie humana y como un derecho subjetivo. El derecho al medio libre de contaminación es considerado como la "directa emanación de su derecho a la vida" y de su integridad física en algunos $\operatorname{casos}^{18}$. Esta orientación se ha visto corroborada en buena medida, por la jurisprudencia judicial ${ }^{19}$.

Una concepción absoluta de las facultades del propietario sobre la cosa objeto del dominio, ha cedido durante el último siglo a una que incorpora nociones de bien público. En efecto, consideraciones ambientales como la restricción a la corta y procesamiento de especies protegidas (Araucaria, Alerce y otras), han ido limitado el otrora derecho de dominio absoluto o totalizante sobre las cosas. ${ }^{20}$

Una visión general ${ }^{21}$ del valor jurídico medio ambiente que exija una relación necesaria con la supervivencia de la especie humana ${ }^{22}$, en algunas circunstancias, adolece del defecto de negar el derecho colectivo general al medio ambiente libre de contaminación. Encontramos, no obstante, excepciones a la generalidad referida en nuestra legislación, fundadas más bien en la necesareidad de proteger la Biodiversidad como un valor colectivo específico ${ }^{23}$.

\subsubsection{Concepción Integradora o Global}

Esta visión cosmológica otorga un valor jurídico al medio ambiente considerado como un todo e integrado con sus diversos elementos ${ }^{24}$. Esta conceptualización omnicomprensiva incluye dentro de sí los recursos naturales.

17 SOTO KLOSS, Eduardo, "El Derecho Fundamental a Vivir en un Ambiente Libre de Contaminación: su Contenido Esencial", en Ga. Jur. 151, p. 22.

Ver causa Rol N²54-89, "Comité Ecológico con Ministro de Transporte y Telecomunicaciones", Corte de Apelaciones de Santiago, en Ga. Jur. 110 (1989), p.108.

${ }^{19}$ Ver causa Rol N¹53-93. "Comité Naci nal Pro Defensa de laofauna y flora, CODEFF", Corte de Apelaciones de Concepción, en Ga. Jur. 163 (1994), p.50.

${ }^{20}$ Por ejemplo, el Proyecto de Recuperación del Bosque Nativo y de Fomento Forestal, contiene restricciones especificas al dominio basadas en consideraciones ecosistémicas. Al efecto, ver el Título VII sobre prohibición de sustitución de especies arbóreas nativas, y el Título VIII, "De las Medidas para la Protección Ambiental". El proyecto de ley fue ingresado en la Cámara de Diputados, Sesión $67^{\circ}$, del 28 de Abril de 1992, p. 101.

21 SOTO KLOSS, (n. 21), p.25. Señala que "sólo, única y exclusivamente les sean reconocidos y los posean las personas, únicas que pueden prevalerce de ellos," refiriéndose a los derechos consagrados en el art. 19 de la Constitución Política, dentro del cual se encuentra en el $\mathrm{N}^{\circ} 8$, a un medio ambiente libre de contaminación.

22

Ver causa Rol N¹31-93. "Beauzemberg con Aguirre"., de Apelaciones de Santiago, en Ga. Jur. 168 (1994), p. 48. La sentencia expresa en su considerando $N^{2} 20$ : "Este derecho -el de protección ambiental- significa que el ser humano tiene la posibilidad jurídica de exigir que cese toda acción que contamine el ambiente en el que dicha persona vive, ya sea que produzca olores desagradables, ruidos que superen las máximas permitidas, aguas contaminadas, gases envenenados, etc..."

${ }^{23}$ Constituyen ejemplos al respecto, el Sistema de Areas Protegidas del Estado (Ley N¹8.362), y el denominado "Libro Rojo" de la Corporación Nacional Forestal, el cual contiene un listado del estado de conservación de las especies vertebradas terrestres en Chile, segunda edición 1993, sin perjuicio de la clasificación y listado incluídos en la nueva Ley de Caza (N¹9.473, D.O. 27.09.96).

24

Sentencia Corte Suprema en caso Lago Chungará constituye un hito sobre el punto (n. 4). 
La destrucción del entorno natural motiva una protección orgánica del ecosistema, ${ }^{25}$ existiendo ejemplos concretos de esa salvaguarda en nuestra legislación ${ }^{26}$. Es así como se ha hablado incluso de un "ecodesarrollo" 27 . Esta visión no obstante no ser aceptada por parte de la doctrina ${ }^{28}$, está presente en nuestra legislación tradicional, pero de manera confusa, incompleta, y en algunos casos, errada. En efecto, podemos distinguir algunas expresiones de la perspectiva integradora del medio ambiente ${ }^{29}$ :

\subsubsection{Concepción Relativa al Patrimonio Paisajístico, Artístico y Cultural ${ }^{30}$}

Entiende al medio ambiente como una entidad compuesta también de elementos no naturales; como todo aquello "que rodea al ser humano" y es digno de ser preservado $^{31}$. El medio ambiente estaría formado, de acuerdo a esta noción, por el "equilibrio ecológico...", y por todo aquello que constituye la preservación del paisaje, vinculando al patrimonio cultural y artístico "32.

Sin embargo, esta concepción es demasiado amplia, imperfecta, y confusa para efectos del establecimiento de tipos penales relativos al medio ambiente. En efecto, es amplia pues podría entenderse como inclusiva de monumentos nacionales, piezas arquitectónicas, etc., concepto extraño al medio ambiente propiamente tal en su concepto natural. Es imperfecta, ya que puede dirigir al intérprete de una norma que incluya tal definición a valorizar ante eventuales transgresiones, más a elementos artificiales que al entorno natural. Es, finalmente confusa, porque, en palabras sencillas, puede el ser humano vivir sin monumentos, pero no sin aire, agua, ríos, o suelos. Por lo anterior, el nivel de protección legal de estos últimos recursos debe ser superior.

Este concepto de medio ambiente como inclusivo del patrimonio artístico y cultural ha sido igualmente criticado ${ }^{33}$ por la doctrina ${ }^{34}$.

\subsubsection{Concepción Salubrista}

${ }^{25}$ KUNSEMULLER (n. 2), p.3.

${ }^{26}$ La ley 18.362 sobre "Sistema Nacional de Areas Silvestres Protegidas del Estado", reconoce al ambiente natural como bien juridico protegido. Citado en Kunsemuller (n. 2), p.6.

27 BAÑADOS MUNITA, Luis, "La Cuestión Económica y el Medio Ambiente desde una Perspectiva Jurisprudencial", en Ga, Jur. 107 (1989), p.3.

${ }^{28}$ SOTO KLOSS, (n. 17), p. 27. Estima que dentro de la protección constitucional del ambiente "No se trata pues del ambiente de los peces, de los minerales, o de los vegetales...sino sólo, única y exclusivamente del ambiente del hombre...".

29 Otra norma reciente, la Ley No18.695 sobre Municipalidades, dentro de las funciones no privativas de esas corporaciones, indica la protección del medio ambiente.

30 Ver la Convención de la Organización Educacional, Cientifica y Cultural de las Naciones Unidas para la Protección del Patrimonio Natural y Cultural Mundial, y la Lista del Patrimonio Mundial, aprobada en París, el 16.11.72, suscrita por Chile.

${ }^{31}$ Ver la definición de medio ambiente contenida en el art. $1^{\circ}$ letra II) de la ley 19.300, que incluye elementos "artificiales de naturaleza física... [y] socioculturales..."

${ }^{32}$ CORDERO VEGA (n. 5) p.47, en referencia a la historia fidedigna de establecimiento de la Comisión de Estudios de la Nueva Constitución, sesión $N^{\circ} 186$, de 1976, intervención del comisionado Sr. Diez.

33 CORDERO VEGA (n. 5), p.25. "..este concepto de medio ambiente, en efecto, se acerca más a entorno que a medio ambiente..."

34 EVANS DE LA CUADRA, Enrique, Los Derechos Constitucionales. Tomo I1, p.380, Ed. Jur., 1986, citado en DOUGNAC RODRÍGUEZ, Fernando, "Las Limitaciones al Derecho de Propiedad como Consecuencia de la Regulación de la Contaminación Atmosférica", en Ga. Jur. 144 (1992), p.13. 
Define el medio ambiente desde el punto de vista de la protección de la salud de la población ${ }^{35}$. Esta ha sido la visión tradicional y más extendida en nuestra legislación ${ }^{36}$.

Podemos citar como ejemplos, el Reglamento sobre "Normas sobre Protección de Aguas en Pro de la Agricultura y la Salud de los Habitantes," ${ }^{37}$ el Código Sanitario que contiene una diversidad de normas en tal sentido ${ }^{38}$, el Código Penal ${ }^{39}$, y el Reglamento sobre Condiciones Sanitarias y Ambientales Básicas en los Lugares de Trabajo ${ }^{40}$, que contiene una visión parcial de medio ambiente pues no puede entenderse, como lo hace ese cuerpo legal que medio ambiente es, simplemente, todo aquello que nos rodea. Todo concepto legal debe ser preciso, y tal objetivo no se cumple en esta conceptualización.

La concepción tradicional de medio ambiente es destacable, pero insuficiente pues, por ejemplo, si se extinguiera una especie animal la salud de la población no estaría en riesgo, pero sí se lesionaría el ecosistema en su conjunto.

Estamos ahora, entonces, en condiciones de analizar la idea de medio ambiente en nuestro desarrollo constitucional y legal reciente, y proyectar un concepto suficiente para asegurar una protección global del valor jurídico medio ambiente en nuestro ordenamiento jurídico, desde la perspectiva de la ciencia penal.

\section{Algunos Conceptos en Derecho Comparado ${ }^{41}$}

La Constitución polaca de 1952 (Art. 71), se refiere a los "valores del ambiente natural...", como la Constitución griega (Art. 24) al "ambiente natural". La Constitución española de 1974 (Art. 45) utiliza la expresión: "medio ambiente adecuado para el desarrollo de la persona..", separado de "la utilización racional de todos los recursos naturales...", facultando al legislador para establecer penas en caso de violación del deber de proteger estos últimos. La Constitución argentina distingue las acciones rela-

35 Alguna jurisprudencia ha corroborado esta orientación. Ver causa Rol N¹7.399. "Tapia con Compañía Cervecerías Unidas S.A.", Corte de Apelaciones de La Serena, Considerando 9.en. Gob. Reg. y Mun 32 (1996), p.143.

${ }^{36}$ La Ley N³.133, sobre Neutralización de los Residuos Provenientes de Establecimientos Industriales, constituye otro ejemplo en tal sentido al regular los residuos que contaminen el aire o puedan dañar las alcantarillas.

37

El D.L. N³.557. D.O. del 09.02.81, Ministerio de Agricultura, en su art. 11, inc. $3^{\circ}$ indica que "En casos calificados, el Presidente de la República podrá ordenar la paralización total o parcial de actividades y empresas artesanales, industriales, fabriles y mineras que lancen al aire humos, polvos o gases, que vacien productos y residuos en las aguas, cuando se comprobare que ello perjudica la salud de los habitantes..."

38

El art, 67 (n. 37), entrega al Servicio Nacional de Salud -hoy Servicio de Salud- la función de "...velar porque se eliminen o controlen todos los factores, elementos o agentes del medio ambiente que afecten la salud, la seguridad y el bienestar de los habitantes..." El art. 89 añade "El reglamento comprenderá normas como las que se refieren a: (a) la conservación y pureza del aire y evitar en él la presencia de materias y olores que constituyan una amenaza para la salud..."

39 El art. 314 (n. 37) sanciona al que "envenenare o infectare aguas...destinados al consumo público, en términos de poder provocar la muerte o grave daño para la salud.." y al que "efectuare otras adulteraciones, en dichas sustancias destinadas al consumo público, de modo que sean peligrosas para la salud..."

40

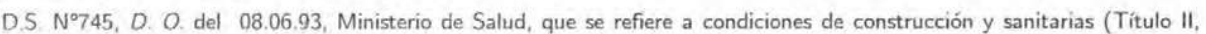
Párrafo I), disposición de residuos industriales líquidos y sólidos (Título II, Párrafo III), evacuación de aguas servidas (Título II. Párrafo IV), ventilación (Título III, Párrafo I), contaminación ambiental (Título IV), contaminantes químicos (Título IV. Párrafo II), y otros.

${ }^{41}$ CORDERO VEGA (n. 5), p. 38, “... [E]ste concepto de medio ambiente, en efecto, se acerca más a entorno que a medio ambiente...". 
cionadas con la "promoción, protección, recuperación y control del medio ambiente y la conservación y aprovechamiento racional de los recursos naturales renovables. ${ }^{42 . "}$

Esta distinción básica entre las expresiones "medio ambiente" y "recursos naturales" está, igualmente, presente en algunos sistemas jurídicos comparados, como también en nuestro sistema jurídico ${ }^{43}$.

\section{Noción de Medio Ambiente Desde la Constitución de 1980:}

El Artículo $19 \mathrm{~N}^{\circ} 8$ de la Constitución de 1980 asegura a todas las personas el derecho a un medio ambiente libre de contaminación. Esta nueva regulación nos merece algunas reflexiones: [a] No existe una referencia a la protección de los recursos naturales, los cuales, según podemos colegir, se consideran comprendidos por el Constituyente dentro del concepto "conservación del patrimonio ambiental" como limitante del derecho de dominio dentro de la "función social de la propiedad" del artículo 19 N²4 de la Constitución; [b] Se eliminó la referencia a la "integridad territorial" ${ }^{44}$, lo que constituye un acierto, por cuanto no se percibe la relación entre el tamaño del territorio nacional, con el hecho de que esté contaminado o degradado su ambiente; y [c] Se reemplazó la expresión "recursos naturales" por "naturaleza" ${ }^{45}$ acercándose a una noción más integral ${ }^{46}$.

La Constitución adopta, en este sentido, una concepción global o integradora de la protección ambiental, visión que se ve corroborada por las definiciones contenidas en la Ley de Bases del Medio Ambiente la cual en su artículo $1^{\circ}$ ha venido a precisar diversos conceptos: "medio ambiente libre de contaminación, protección del medio ambiente, preservación de la naturaleza y conservación del patrimonio ambiental."

Tal es la visión globalizante o integradora que adoptó el legislador en la Ley 19.300 que, entendemos, exageró al incluir dentro de la definición de medio ambiente elementos "socio-culturales". Ha sido apropiado comprender los recursos naturales dentro del medio ambiente en una relación de género a especie, pero desacertado al incluir elementos no naturales.

El concepto de medio ambiente utilizado mayoritariamente en la jurisprudencia y doctrina chilenas es de carácter integrador pero, sin embargo, marcadamente individualista. Es así como estiman algunos que el $N^{\circ} 8$ está a dentro del capítulo sobre "Las Garantías Individuales", y a continuación de los llamados derechos personalísimos, incluso antes del derecho de propiedad. La consecuencia práctica sería que sólo en cuanto el derecho particular del individuo al medio ambiente libre de contaminación se vea afectado, será accionable ante la judicatura.

\footnotetext{
42 MARTÍNEZ, Víctor, Ambiente y Responsabilidad Penal., en Ed.. Depalma, Buenos Aires (1994).

${ }^{43}$ En el Senado de la República existe una Comisión de Medio Ambiente y Recursos Naturales.

${ }^{44}$ KUNSEMULLER (n. 2), p.5.

${ }^{45}$ Ver causa Rol N¹5-92, "Albornoz Vera con Sociedad Maderas de Aysén S.A.". Corte de Apelaciones de Coyhaique, en Rev. Gob. Reg. y Mun 32 (1996), p. 166, que en su considerando $7^{\circ}$ expresa "...dicho acto al afectar la naturaleza misma, y al contaminar el aire y cauces de agua resulta atentatorio a toda norma civilizada de convivencia del hombre con su medio y siendo la preservación de la naturaleza y conservación del patrimonio ambiental preocupación del Estado..."

46

CORDERO VEGA (n. 5), p. 44; "...se deduce que la Constitución entiende por medio ambiente todo cuanto esté relacionado con la naturaleza estricto sensu...".
} 
Esta orientación excluye una relación con grupos humanos, o la comunidad misma, y niega su carácter de derecho colectivo. Esta idea ha sido criticada de manera importante en la doctrina nacional, ${ }^{47}$ y parece ser insuficiente para el propósito de establecer figuras penales protectoras de manera global del valor jurídico "medio ambiente".

\section{Ambientales \\ III. Consideraciones Político-Legislativas para la Criminalización de Ofensas}

\section{Principio de Intervención Mínima}

Dentro de este análisis ha de tenerse en cuenta la concurrencia y aplicación del denominado "principio de intervención mínima", el cual exige para la criminalización de conductas, la selección de los atentados más graves, que lesionan o ponen en peligro el bien jurídico "medio ambiente", es decir, cuando la conducta acarree un daño irreversible al ecosistema, o ponga en riesgo importante la vida, o salud de las personas.

El medio ambiente aparece como susceptible de protección penal en un primer orden, puesto que la convicción de nuestra ciudadanía lo considera como valioso. $\mathrm{Pa}$ radigmático sobre el punto ha sido la dictación de la Ley de Bases del Medio Ambiente, y la creación de la Comisión Nacional del Medio Ambiente, existiendo además una política pública sobre el tema, que se expresa por ejemplo, en el desarrollo de un plan de descontaminación. A un nivel normativo la presencia de su relevancia arranca ya desde la dictación de la Constitución de 1980, consagrando el denominado "recurso de protección" para su salvaguarda. La reserva con que el Constituyente dotó de protección a dicha garantía de "vivir en un medio ambiente libre de contaminación" a través de la acción de protección plantea al menos que históricamente su defensa a un nivel normativo no podía ser plena.

Observamos además que si bien ha existido un aumento de la conciencia pública de los graves riesgos que implica el fenómeno de la contaminación y el racional uso de los recursos naturales, dicha preocupación no se ha trasladado al debate dogmático nacional sobre el ecosistema como bien jurídico merecedor de protección ${ }^{48}$, situación que sí ha ocurrido en otras latitudes ${ }^{49}$. El referido debate es básico si no ha de caerse en la citada tipificación irreflexiva y sin sustento político criminal, y ha de proyectarse en resolver un punto crucial del contenido del bien jurídico "medio ambiente", si éste se

47 TALLAR DELUCHI. Fernando, Aspectos Constitucionales del Derecho a Vivir en un Medio Ambiente Libre de Contaminación. Escuela de Graduados de la Facultad de Derecho, Universidad de Chile (1997), pp.4-11.

48

En efecto, los documentos dogmáticos relativos al área penal del medio ambiente que conocemos no son recientes, $y$ a un nivel de publicaciones nacionales no se revela una gran preocupación siquiera sobre el punto. Verbigracia, YAÑEZ, Sergio y NÁQUIRA, Jaime, "Derecho Penal del Entorno", ponencia al Primer Congreso sobre Derecho Penal del Entorno, 1977.

49

Como así parece haber ocurrido en España, comunidad en que se debate incluso la autonomía del ecosistema para erigirse como bien jurídico merecedor de protección. RODAS MONSALVE, Julio César. Protección Penal y Medio Ambiente. PPU, Barcelona 1993, p. 133

50

ALBIN, Eser. "Derecho Ecológico" en Rev. Derecho Público, España, 1985. Citado por CASTILLO SÁNCHEZ, Marcelo, en Régimen Jurídico de Protección del Medio Ambiente, Ed, Bloc, Santiago (1994). 
erige como un bien o valor en sí, o si necesariamente en lo mediato se haya la vida, integridad y salud del ser humano.

La necesidad de un debate amplio y nacional de todos los partícipes sociales vinculados al tema, se refuerza en el hecho que a nivel comparado, en el campo penal existe un amplio consenso de la importancia del medio ambiente como bien jurídico penal ya desde el XII Congreso Internacional de la Asociación Internacional de Derecho Penal de 1979. Posiciones más aceptables postulan la protección del medio ambiente en cuanto tal, debido a que ello permitiría que el bienestar particular pueda ceder ante el género humano y la conservación de la naturaleza ${ }^{50}$.

Por otra parte, la existencia de una necesidad de protección del medio ambiente a través del derecho penal debiera confirmarse mediante el análisis de la importancia de las sanciones civiles, y de su eficacia para controlar fenómenos o conductas contaminantes. Conspira en contra de dicho análisis la escasa vigencia de un sistema de responsabilidad civil por el daño ambiental, y la inexistencia de una jurisprudencia sobre el particular, que permita dar indicios de eficiencia. Se ha podido observar que la preocupación ciudadana y la resolución de asuntos en los tribunales se ha vinculado más bien por la incidencia ambiental de proyectos que incidirían en el entorno.

Resulta relevante señalar que en opinión de algunos autores existe un consolidado consenso en el derecho comparado, sobre la conveniencia de la herramienta penal dentro de un sistema de protección integral y pluridimensional que involucre las distintas áreas del ordenamiento jurídico.

Ahora bien, y no obstante que se pudieran sortear con éxito las consideraciones anteriores, no debe confundirse la necesidad de la intervención penal con su intensidad, es decir, el derecho penal cuando interviene no abandona su fragmentariedad, de tal forma que será necesario graduar los atentados al entorno, desde ya aparece plausible sostener que no todos los ataques al ecosistema sean penalmente relevantes. Dicha magnitud de presencia aparece concordante con el postulado de que la actividad administrativa de prevención y control es una prioridad dentro la lucha por la preservación del medio ambiente.

\section{Delito de Peligro}

Un tópico que incide en la criminalización de conductas contra el medio ambiente, es que atendido que la dañosidad de las conductas se verifica mediante acumulación, y por la general intervención de una pluralidad de sujetos en su causación se vislumbra la necesidad de tipificar dichas conductas mediante la formula de delitos de peligro, que atendido el actual contenido de nuestro ordenamiento Constitucional, deberán ser de peligro concreto. Delitos de peligro son aquellos que se perfeccionan por el solo riesgo o posibilidad de que ocurra un detrimento del bien jurídico tutelado, sin que el efectivo menoscabo de éste, eventualmente, sobrevenido con posterioridad, tenga mayor trascendencia para efectos de penalidad como sucede por ejemplo, con el delito de tráfico ilegal de estupefacientes.

Se argumenta en favor de esta solución típica que la configuración del delito de esta manera produce un importante efecto preventivo general sobre los posibles infractores, habiéndose regulado de esta forma en España y Alemania. 


\section{Normas penales en blanco}

Como forma de tipificación en particular, se estima modernamente que en el ámbito del medio ambiente el recurso a normas penales en blanco es inevitable, dada la especificidad y complejidad de las conductas, unido a la existencia de elementos valorativos en ella. Situación que dentro de la dogmático jurídico penal nacional parece estar aceptada, no existiendo gran polémica en torno a su constitucionalidad.

La relevancia de la remisión a normas de tipo administrativo mediante tipos penales en blanco estaría dada en cuanto dicha norma de inferior jerarquía estará fijando los límites precisos -y naturalmente variables- del riesgo permitido.

Esta clase de tipos penales se daría, más propiamente, tratándose de normas de calidad ambiental.

\section{Antijuricidad ambiental}

Se presenta en este contexto de análisis, que la regulación típica de atentados contra el medio ambiente requiere en forma ineludible, de la existencia de una normativa relativamente completa y coherente en materia ambiental, de tal forma, que los sujetos que intervengan en esta área tengan una relativa certeza de lo antijurídico, y estén en la posibilidad de adquirir a un nivel de culpabilidad una conciencia de su obrar antijurídico. En este contexto, cobran suma importancia los permisos para actividades riesgosas del medio ambiente, la existencia de normas de calidad de aire, de agua, etcétera.

Este aspecto del análisis no ha dejado de crear situaciones complejas a nivel comparado, por ejemplo, existen cuestionamientos respecto al carácter formal que tendrían este tipo de ilícitos, naturaleza que se traduciría en que la comprobación de la peligrosidad para el bien jurídico se centraría en la mera exigencia formal de una autorización previa, de este modo, la complejidad de la regulación de este tipo de atentados juega en su contra, pasando casi inadvertidamente a tutelar aparentemente funciones administrativas de autorización en torno al bien jurídico. Autores italianos en torno al problema llegan a sostener la importancia de la tutela de funciones administrativas como medio protector, retrucándose que dicho tipo de argumentaciones revelan una "estafa de etiquetas". Efectivamente, las exigencias modernas del principio de lesividad imponen poner en contacto la conducta y el bien jurídico, de modo tal que la prohibición ha de dirigirse a aquellas conductas que ponen en peligro - aunque sea potencialmente - al bien jurídico, y no puede vincularse jamás con meras transgresiones administrativas que no implican riesgo para lo tutelado.

Se advierte en derecho comparado, como es previsible por lo demás, que un abuso de regulaciones que se dirigen a la protección de contravenciones administrativas conforme lo ya apuntado, tiende a diluir los límites entre el ilícito penal y el administrativo. Dicho fenómeno ha de ser tenido en especial consideración a la hora de enfrentar la redacción particular de los tipos penales de una parte; y de otro lado, planteará exigencias a nuestra jurisprudencia en orden a sentar criterios claros de incriminación cuando exista una efectiva lesión o puesta en peligro del bien afectado. Cobra relevancia a esta hora el tema ya adelantado de la causalidad o los criterios de imputación objetiva dentro de estos ilícitos. Por otro lado, el alejamiento de la conducta con res- 
pecto a la lesión o puesta en peligro de bienes tutelados, provocaría un sensible menor auto y heteroreproche por la conducta realizada, disminuyendo la eficacia preventivo general de la tipificación de este tipo de conductas.

Por otro lado, la tipificación mediante tipos abiertos y plenos de referencias a cumplimiento de mandatos administrativos implica un reenvío de la potestad punitiva al ejecutivo-administrador, con el previsible riesgo del crecimiento explosivo de regulaciones, unido a que la generación de dichas normas generalmente se está guiando por criterios propios del área y no implica que se tengan a la vista los conceptos modernos de intervención penal.

Significativo es destacar que dentro de la reforma procesal penal alemana, se ha sostenido el criterio de la protección de los elementos biológicos que constituyen la envoltura natural en que se desarrolla la vida del hombre, y no la mera tutela de leyes administrativas $^{51}$.

\section{Sujetos de la Responsabilidad Penal Ambiental}

El análisis de los sujetos pasivos como activos de la responsabilidad penal ambiental requiere, necesariamente, o bien, una adopción o adecuación de los conceptos y nociones del Derecho Penal clásico, o de una innovación doctrinaria que recoja la realidad moderna del fenómeno de contaminación ambiental.

A continuación se entregan ciertas ideas acerca del concepto de sujeto de responsabilidad penal ambiental, desde una perspectiva más pragmática y no excesivamente concordante con la dogmática penal tradicional.

\section{Sujeto Pasivo}

El sujeto pasivo en los delitos ambientales sería la colectividad en su conjunto. En efecto, según hemos podido observar, un mal colectivo, afecta a la comunidad entera, y requiere también soluciones provenientes de la sociedad como un todo.

\section{Sujeto Activo. Personas Jurídicas}

Igualmente problemática es la categorización de los sujetos responsables del deterioro ambiental, distinguiéndose en forma general: sujetos que institucionalmente están encargados de la tutela del ambiente, sujetos que desarrollan una actividad económica y al realizarla generan condiciones negativas, y sujetos que ocasionalmente contribuyen a su deterioro.

En este sentido, es empíricamente comprobable que los causantes de daños comparativamente más graves (en materia de seguridad nuclear, por ejemplo) al medio ambiente son generalmente personas jurídicas, más que personas naturales, las cuales eluden el cumplimiento de normas del entorno más severas, valiéndose del aparato burocrático, en un punto de conexión con la criminalidad económica, y planteando necesariamente el problema de la determinación de la autoría, y de la posibilidad de existencia de participación, el tema de la responsabilidad penal de las personas jurídi-

${ }^{51}$ RODAS MONSALVE $(n, 44), p .144$. 
cas, o la desestimación de la personalidad jurídica cuando ella se ha utilizado para delinquir, o la institución de la actuación por otro.

\section{Eficacia de la Represión Penal en caso de Ofensas Ambientales.}

Dentro del análisis de la introducción de nuevos tipos penales es siempre necesario, conforme a modernos criterios, verificar que la criminalización de conductas por su sola incorporación disminuya los hechos o atentados con los bienes tutelados, es decir, que cumpla su función general preventiva. Sobre el punto, se sostiene la necesidad de que todo proceso legislativo - dentro del cual los ilícitos ambientales no son una excepción- contemple un objeto preventivo y, en definitiva, la decisión de criminalizar esté avalada por investigaciones criminológicas relativamente concluyentes. En el medio nacional, si bien se ha podido realizar un catastro de los principales problemas ambientales de nuestro país, no se conocen propiamente estudios criminológicos sobre el tema. Dicha ausencia, sirva de consuelo, no es solo propia de nuestro medio, sino que increíblemente también se han producido en los procesos legislativos de países con una mayor solvencia cụltural y dogmática que la nuestra ${ }^{52}$.

Puede advertirse en tal sentido, una falta de interés de la criminología por abordar dicho fenómeno, probablemente por la falta de conciencia de la dañosidad social unida la realización generalmente de actividades lícitas. A ello se puede agregar la ineludible complejidad técnica de este tipo de fenómenos, y en una aparente marginación de la criminología tradicional de la denominada "macrocriminalidad", en preferencia por la criminalidad personal.

\section{Concepto legalista o reglamentario de medio ambiente}

Como hemos observado, es insuficiente un simple enfoque parcial y una orientación excesivamente individualista del derecho consagrado en el $N^{\circ} 8$ del Artículo 19 de la Constitución, el cual ha sido seguido de forma importante por la jurisprudencia chilena.

Ahora bien, con la finalidad de precisar el contenido y alcance de un concepto integrador de medio ambiente, y considerando nuestra tradición jurídica, entendemos que aquel concepto debería: (a) ser definido en nuestra Carta Fundamental de manera global, por cuanto las amenazas ambientales son, también globales; y (b) ser regulado con fines penales desde una perspectiva reglamentaria o legalista, definiéndose la técnica jurídico y político-criminal que se seguirá, sobre la base de lo expuesto anteriormente.

Tal concepto legal de medio ambiente debería también tomar en cuenta las connotaciones económicas de su definición ${ }^{53}$, pues existe un nivel de degradación inevi-

52 La crítica de falta de estudios criminológicos en la elaboración de leyes penales también se dirigieron contra la reforma penal
alemana de 1980 que introdujo el título de la criminalidad ambiental. Incluso autores como Herzog dejan entrever que influyó
en una decisión precipitada de criminalización la influencia de un año electoral, citado por RODAS MONSALVE (n. 44),
p.151.
De manera reciente los Tribunales han optado en algunos casos por enfrentar determinados asuntos sometidos a su cono-
cimiento desde la perspectiva de la garantía constitucional ambiental. Ver causa Rol N'274-89-P, "Osses con Serey", Corte de 
table en toda actividad humana ${ }^{54}$ y por lo demás necesario para el desarrollo de la vida humana.

Sugerimos el reconocimiento legal de la existencia del delito ambiental, o el establecimiento de la contaminación como tipo penal. La conceptualización de aquella definición legal se haría desde una perspectiva reglamentaria. "Contaminar" ${ }^{55}$, sería un concepto puramente dogmático: el exceso de uso o degradación por sobre los límites ${ }^{56}$ señalados en la ley y los reglamentos ${ }^{57}$. La contaminación como delito será transgredir en cada caso señalado por la ley, los límites fijados por ésta, bien sea, por ejemplo, mediante la forma de emisión de gases por sobre ciertos niveles permitidos establecidos en la norma, el vertimiento de contaminantes por sobre los límites tolerables indicados en la ley, la amenaza concreta a elementos de la Biosfera o la depredación de especies esenciales para la supervivencia de la cadena de la existencia ${ }^{58}$.

La aplicación práctica de la regulación penal del medio ambiente estaría dada por un marco fuera del cual sería penalizada toda degradación que excediera de manera desmesurada ${ }^{59}$ los límites así fijados, que constituya más que una mera "alteración del medio ambiente", y que arriesgue o afecte al ser humano, su entorno o a grupos humanos.

La sentencia de la Corte Suprema en el caso Chungará ${ }^{60}$ es un paso importante en la interpretación globalizante del concepto constitucional de medio ambiente ${ }^{61}$.

Apelaciones de Santiago, en Ga. Jur. 110 (1989), p.48

54 Ver causa Rol N¹.929-95, "Emeres Ltda. con Municipalidad de Til-Til", Corte de Apelaciones de Santiago, Recurso de Amparo Económico, Considerando $7^{\circ}$.

55 En la voz "contaminar" se incluiría la introducción de especies exóticas, contaminación por vertimiento de desechos, radioactiva, atmosférica, por relaves mineros, desperdicios domésticos, fertilizantes y pesticidas, por humo o neblina tóxica, por captación de líquidos percolados, emanaciones de olores pestilentes, por lluvia ácida, emanaciones de residuos de plomo, contaminación de aguas continentales, marítimas o subterráneas, de la pesca, aguas costeras, fondos marinos, recursos marinos vivos, del mar por hidrocarburos, el comercio de especies amenazadas, contaminación proveniente de fuentes terrestres, contaminación radiactiva, la fauna y flora, maderas, accidentes nucleares, minerales, etc.

${ }^{56}$ Este concepto reglamentario de contaminación ha sido recogido por la jurisprudencia. Al efecto, ver (A) "Calbacho y otros con Fábrica de Carrocerías", Corte de Apelaciones de Santiago, Rol N57-89, en Ga. Jur. 109 (1989), p.38; (B) "Urízar y otros con Zarzar", Corte de Apelaciones de Arica, Rol N³.306, en Ga. Jur. 154 (1993), p.30; (C) "Mardones y otros con Laborderie". Corte Suprema de Justicia, Rol N²2.751, en Ga. Jur. 166 (1994), p.37; (D) "Marín Palacios con Alcalde de la Municipalidad de Las Condes", Corte de Apelaciones de Santiago, Rol N³.302-94, en Rev. Gob. Reg. y Mun. 26 (1995), p.85, considerando $4^{\circ}$; (E) "Affeld Aeschlimann y otros con Gerente Regional de Multitiendas Ripley", Corte Suprema de Justicia, Rol N²1.695, considerando $2^{\circ}$. Rev. Gob. Reg. y Mun. 32 (1996), p.130; (F) "Instituto de Ecología de Chile con Compañía Minera Santo Domingo Ltda.", Corte Suprema de Justicia, Rol N¹6.781, en Rev. Gob. Reg. y Mun. 32 (1996), p.134, considerando 2; (G) "Saavedra López con Vallejos Choydeng", Corte Suprema de Justicia, Rol N².215-96, en Ga. Jur. 197 (1997), p. 45, considerando $1^{\circ}(\mathrm{a})$

${ }^{57}$ EI D.S. N¹44, art. 8 letra b) establece la facultad del Servicio Nacional de Salud de "fijar, cuando así lo estime conveniente, las concentraciones máximas permisibles de cualquier contaminante..."

58 CORDERO VEGA (n. 5), p.33.

${ }^{59}$ En la Sesión $N^{\circ} 14$, del 03.08.93, con motivo de la discusión de la Ley $N^{\circ} 19.300$, el senador Diez hizo referencia a los límites máximos permisibles, indicando que "cuando se sobrepasen tales límites, estaremos en presencia de contaminación..." Añadiendo, luego, "¿qué será contaminar? Será exceder una norma legal"

60

El Senador Díez ( $n, 60)$, señaló que "el medio ambiente y el patrimonio ambiental se afectan negativamente y no se preserva la naturaleza cuando se les contamina, poniendo asi en peligro, por rompimiento del equilibrio natural del ecosistema, el elemento ambiental que sirve de sustento a la existencia misma, al desenvolvimiento y desarrolio de la humanidad toda, siendo esto, precisamente lo que cautela nuestra Constitución" (Considerando $5^{\circ}$, segundo párrafo). 


\section{Algunas notas del Derecho Comparado sobre Responsabilidad Criminal por Daño Ambiental.}

\section{Legislación Brasileña}

La Constitución Federal de Brasil de 1988 en su artículo 225, Sección 3o faculta al legislador para establecer sanciones penales y administrativas para los responsables de daño ambiental, además de la obligación de compensar el daño causado.

Los delitos y contravenciones en contra del medio ambiente están contenidos en el Código Penal y en la Ley de Contravenciones Penales, como asimismo en una variedad de legislación específica ${ }^{62}$.

Sin embargo, para nuestros efectos, la figura más interesante la constituye el denominado "Delito de Contaminación" (Ley № 6.938, de 31/08/1981) ${ }^{63}$. Además, recientemente, una nueva ley sobre Delitos Ambientales fue aprobada por el Senado y remitida a la Cámara de Diputados para su ulterior consideración. El proyecto estable$\mathrm{ce}$, entre otras innovaciones, el principio de responsabilidad objetiva por delitos ambientales $^{64}$. En la práctica, el proyecto introduce una mejor individualización de la responsabilidad ambiental, y establece un sistema de penalización alternativo a la prisión $^{65}$.

\section{Legislación Estadounidense}

Esta es, sin duda, una de las legislaciones ambientales más avanzadas en el mundo y, por lo mismo, no cercana al desarrollo incipiente del sistema jurídico ambien-

\footnotetext{
${ }^{61}$ DOUGNAC (n. 34), p.16.
}

62 Existen varios ejemplos: (A) El Código Forestal (Ley N² 4.771, de 15/09/1965), contiene tipos penales referidos, entre otros, a la destrucción o daño o la corta de árboles en bosques de preservación permanente, sin permiso de la autoridad competente, la penetración en tales bosques portando armas, substancias o instrumentos propios para la caza prohibida o para la exploración de productos o subproductos forestales, sin estar premunido de licencia por la autoridad competente, el daño a los Parques Nacionales, Estatales o Municipales, así como a las Reservas Biológicas, como otras figuras típicas muy estrictas. (B) El Código de Caza (Ley n² 5.197, de 03/01/1967). penaliza como "un crimen con pena de reclusión de dos a cinco años, entre otras conductas, ..."el comercio de especies de la fauna silvestre y de productos u objetos que impliquen su caza, persecución, o destrucción". Llega incluso a denegar la posibilidad de fianza respecto de estos delitos (art. 34). (C) El Decreto Ley № 2.848 . de 07/12/1940 contiene figuras penales tales como el Incendio doloso o culposo en bosque, el daño en bosque particular, o en bosque de Unidad, Estado o Municipio, el daño por abandono de animales en bosques, el envenenamiento de agua potable o de substancia alimenticia o medicinal, y la polución de agua potable (Trad. Dante Figueroa Hernández, 1997).

El art. 15 sanciona al que "...expusiere a peligro la inocuidad humana, animal o vegetal o estuviera tornando más grave la situación de peligro existente", con la pena de reclusión de uno a tres años de reclusión y multa. Establece un aumento al doble de la pena para el caso en que: (1) Resultare: a) Daño irreversible a la fauna, la flora o el medio ambiente; b) Lesión corporal grave; (2) La polución provenga de una actividad industrial o de transporte; (3) El delito sea perpetrado durante la noche, en domingo o feriado. Además, extiende la responsabilidad penal por los mismos delitos a la autoridad competente que deja de promover las medidas tendientes a impedir la práctica de las conductas punibles descritas (Trad. Dante Figueroa Hernández. 1997)

64

Otra innovación del proyecto es el establecimiento de la responsabilidad criminal de las personas jurídicas en caso de daño ambiental, haciendo responsable a la persona del accionista principal, director, administrador, gerente, etc., con la imposición de multas, suspensión de actividades, interdicción permanente o temporal de la empresa, y otras penas.

65

Por ejemplo, la "prestación de servicios a la comunidad" en que el sancionado puede ser forzado a trabajar sin derecho a remuneración en parques protegidos o áreas protegidas, interdicción temporal de derechos, que impide al degradador ocupar oficios o cargos públicos e incluso contratar con el gobierno, además de la revocación de la eventual licencia para explorar recursos naturales. También se requeríá la reparación de daños a fin de imposibilitar al infractor de beneficiarse de la suspensión del proceso (Trad. Dante Figueroa Hernández, 1997) 
tal chileno. Existe una abundante normativa sectorial en materia de, por ejemplo, control de pesticidas, sustancias tóxicas, manejo de zonas costeras, especies en peligro de extinción, recursos forestales, superficies minerales, agua potable, polución de los océanos, contaminación por petróleo, disposición de desechos sólidos, manejo de suelos, y otros. La mayoría de estos cuerpos legales determinan tipos penales específicos, detallados y establecen figuras de responsabilidad penal objetiva. ${ }^{66}$

El Departamento de Justicia tiene la titularidad en el ejercicio de la acción penal pública por violación a estatutos ambientales. En tal sentido está revestido de un poder de discrecionalidad en el ejercicio de tales acciones en contra de transgresores. Los procesos criminales ambientales otorgan especial relevancia a las autodenuncias de los querellados, como a su cooperación con el gobierno federal en la mitigación de los efectos del acto contaminante ${ }^{6}$. Baste con decir esto pues escapa a nuestro alcance desarrollar ei tema con mayor detenimiento.

\section{Conclusión}

La evolución reciente y creciente de la importancia del entorno para la supervivencia de la especie humana, y la toma de conciencia paulatina de la ciudadanía en torno al valor específico del medio ambiente, la Biósfera y sus componentes, han tenido un fruto perceptible, primeramente, a nivel de convenciones internacionales (Convenio de Basilea, el Protocolo de Montreal, la Convención sobre las Especies en Riesgo de Extinción, son sólo algunos ejemplos), las cuales han tenido un importante impacto en las legislaciones nacionales.

Chile no ha sido una excepción al respecto, existiendo una protección al medio ambiente de carácter inorgánico, parcelado y más bien como una respuesta a fenómenos fragmentarios específicos.

Dentro de este contexto, y teniendo a la vista que la protección penal existente en el país del bien jurídico medio ambiente, es incompleta y generalmente ineficaz, se refuerza la necesaria adopción de algunas decisiones como las siguientes: [a] La introducción a nivel constitucional de la definición de medio ambiente en su concepción integral, ya consagrada por la jurisprudencia judicial, primero y, últimamente, por la Ley de Bases del Medio Ambiente; [b] Una reforma en el mismo sentido facultando expresamente al legislador para fijar figuras penales protectoras del medio ambiente; [c] Que la legislación protectora del medio ambiente que se introduzca tenga un carácter ecosistémico; [d] Que se establezcan tipos penales de peligro concreto, o bien tipos penales en blanco a fin de permitir al ejecutivo-administrador adecuar la norma a las realidad específica del país en cada caso; [e] Que se establezca la posibilidad de que

66

Solo a guisa de ejemplo, pueden mencionarse: [a] La Ley Federal sobre Control de Insecticidas, Fungicidas y Pesticidas, Sec. 1361 (b), que sanciona con prisión al distribuidor comercial que distribuye o vende pesticidas o herramientas que, intencionalmente, viola la citada ley; [b] La Ley sobre Control de Sustancias Tóxicas, Sec. 2615(b), que impone la pena de prisión a quien intencionalmente o deliberadamente viola cualquier norma sobre permisos y autorizaciones establecidas en la ley; [c] La Ley sobre Especies en Peligro de 1973. Sec. 1540(b), que penaliza a quien intencionalmente viola cualquier disposición de la ley relativa a permisos o certificados; y [d] La Ley Federal sobre Contaminación del Agua, Sec. 1319(c), que establece penas de prisión tanto para el caso de transgresiones culposas, como para el caso de transgresiones intencionales (Trad. Dante Figueroa 67 Hernández, 1997).

GLASS GELTMAN, Elizabeth. Environmental Law and Business. Cases and Materials, Ed. Michie, Contemporary Legal Education Series, p.119. 
algunos delitos ambientales consideren un tipo de responsabilidad penal tratándose de personas jurídicas con un potencial destructor ecológico importante; $\mathrm{o},[\mathrm{f}]$ finalmente, que sin llegar a establecerse figuras objetivas como existen en materia de seguridad y daño nuclear, se entreguen elementos al sentenciador para asumir presunciones judiciales produciéndose daños importantes al ecosistema.

Otras medidas más específicas deberían consultar la adopción del principio normativo, reglamentario o legalista para el establecimiento de figuras penales ambientales, con referencia, necesariamente, a leyes penales en blanco tratándose de normas de calidad ambiental. Una opción válida la constituiría, igualmente, el establecimiento de delitos de peligro concreto para el medio ambiente, con ocasión de ofensas graves y globales.

El efecto inhibidor y preventivo de la norma penal ambiental puede ser tenido en cuenta al momento de legislar, pero no puede una decisión político-criminal en tal sentido sólo confiarse ni limitarse a tal finalidad.

Sirva este artículo como un eslabón dentro del punto de partida para el necesario debate que sobre la penalización de ofensas ambientales debe darse en el futuro cercano en Chile, añadiendo otra pequeña revolución jurídica a la ciencia penal chilena actual. 